\title{
Study on the Cracking Mechanism of YQ450NQR1 High-Strength Weathering Steel
}

\author{
J. S. Qing, ${ }^{a}$ X. D. Duan, ${ }^{\text {b }}$ M. F. Xiao, ${ }^{\text {b }}$. Q. Li, ${ }^{\text {b }}$ M. Liu, ${ }^{b}$ Q. Liu, ${ }^{c}$ H. F. Shen ${ }^{\mathrm{a}, 1}$ \\ ${ }^{a}$ Key Laboratory for Advanced Materials Processing Technology, Ministry of Education, School of \\ Materials Science and Engineering, Tsinghua University, Beijing, China \\ b Pansteel Group Co. Ltd., Panzhihua, Sichuan, China \\ c State Key Laboratory of Advanced Metallurgy, University of Science and Technology Beijing, \\ China \\ ${ }^{1}$ shen@tsinghua.edu.cn
}

YQ450NQR1 high-strength weathering steel is prone to cracking. The cracking patterns and morphology were detected by metallographic and scanning electron microscopies. The decarburized layer around the cracks is indicative of their origination in the continuous casting bloom. Then, the controlling factors were established by analyzing the carbon content of molten steel, residual elements in the alloy, purity and performance of the mold powder, and secondary cooling water flow of the mold. Results show that the process optimization reduced the cracking reject ratio from 3.5 to $0.78 \%$.

Keywords: high-strength weathering steel, cracking, decarburization layer.

Introduction. YQ450NQR1 weather-resistant steel with the strength exceeding $450 \mathrm{MPa}$ is a special steel for the beam production of train trucks developed in China [1-3]. Due to the addition of alloying elements such as $\mathrm{Cu}(0.2 \sim 0.4 \%), \mathrm{Ni}(0.15 \sim 0.35 \%)$, and $\mathrm{Cr}(0.4 \sim 0.6 \%)$, cracking is often formed near the continuous strand surface. In order to meet the rapid development of railway transport, as well as requirements for "heavy load, high speed and efficiency" of trucks, the steel must have good weather resistance and welding performance with high-strength and tenacity [4-6]. The production practice of a steel mill in recent years showed that there was a rupture defect on the surface of this steel, as well as cracking rate fluctuations $[1,2]$.

Cracking is one of the surface defects of YQ450NQR1 steel. These defects are rough, deep and irregular with serious decarburization, and appear in the chevron or zig-zag pattern on the bloom surface [1-3]. Rupture defects are the main drawbacks of the steel waste; therefore, it is necessary to study its cracking mechanism so as to effectively control the cracking defects. In this study, the cracking patterns and morphology were detected by metallographic and scanning electron microscopes. Based on the degree of decarburization formed around the cracks and the distribution characteristics of oxide, the influencing factors were explored and technical measures were developed to improve the quality of YQ450NQR1 bloom.

1. Production Status of YQ450NQR1 High-Strength Weathering Steel. The rupture defects of YQ450NQR1 steel in the plant were subdivided into two types: long legs and short legs of the beam products. Although these two types of defects occurred in different locations, their appearance was basically consistent. Figure 1 shows the macroscopic morphology of cracks in the YQ450NQR1 steel. It can be seen that defects of the material are mainly surface cracks accompanied with tongue-like scars, and cracks on the surface are extended along the rolling direction. 


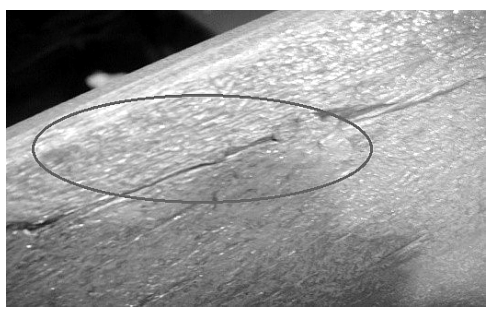

a

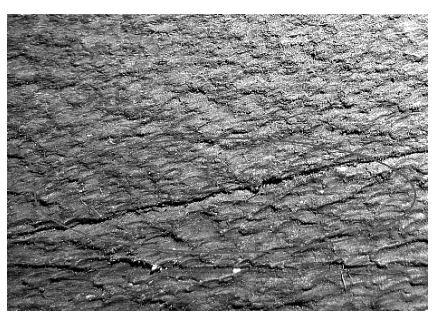

$\mathrm{b}$

Fig. 1. The optical morphology of cracks in the long leg beam (a) and the short leg beam (b) of YQ450NQR1 high-strength weathering steel.

Cracks in the long and short leg beams of the YQ450NQR1 steel were observed along the cross section with the metallographic microscope. Figure 2 shows that the crack in long leg beam is elongated and extends from the surface to the inside, and the largest opening is near the surface gradually tapering along the depth direction. The branching occurs in the tail of the crack and is eventually supressed due to rolling deformation. The extension length in the depth direction exceeds $10 \mathrm{~mm}$. There is an obvious trend to extend to the edge in the depth direction.

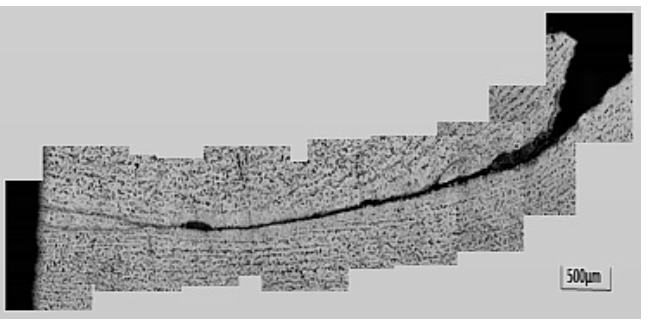

a

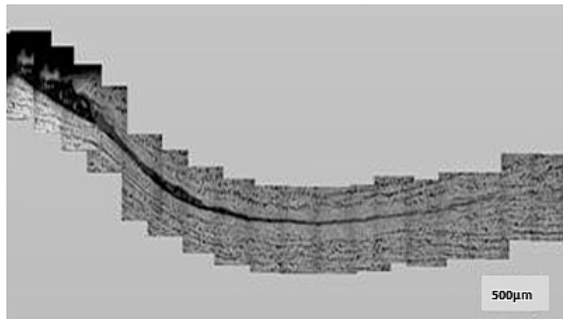

$\mathrm{b}$

Fig. 2. The microscopic morphology of cracks in the long leg beam (a) and the short leg beam (b) of YQ450NQR1 high-strength weathering steel.

The crack in short leg beam is elongated and extends from the surface to the inside, the crack opening is large, and the crack is gradually tapering in the depth direction until it is supressed. The extension length of the crack exceeds $6 \mathrm{~mm}$ and there is an obvious trend to extend to the edge in the depth direction.

It can be seen from Fig. 3 that the ferrite content around the crack increases obviously when the crack develops in the depth direction. In Fig. 3b, there is a significant white color near the crack, as compared with the substrate as well as the significant decarburization layer.

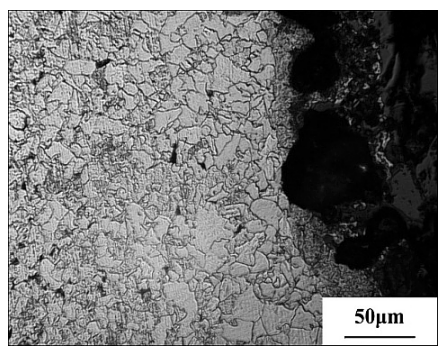

a

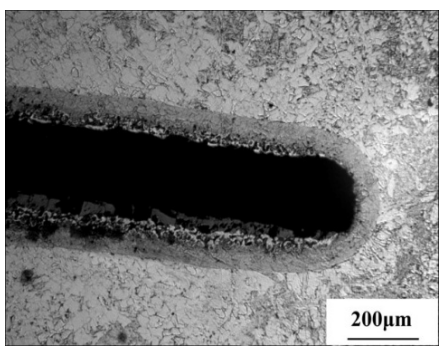

b

Fig. 3. Microstructures near cracks (a) and near cracks with the substrate (b). 
YQ450NQR1 is a low-carbon microalloyed steel. If the surface of the continuous casting bloom has been cracked and the oxide layer is not removed, it will meet the conditions of decarburization near the crack during the heating process. In the subsequent rolling process, the oxidized and decarburized crack cannot be welded and will become a surface defect of the rolling material. It can be seen that there is obvious decarburization phenomenon for YQ450NQR1 steel rolling material, which can be used as the sufficient condition of the fact that crack comes from the casting bloom.

2. Cracking and Decarburization Layer. The source of cracking in YQ450NQR1 steel can be subdivided into two categories: (i) the cracks on the surface of the continuous casting bloom are left to the surface of the rolling material; (ii) cracks are caused by improper rolling process. There are significant differences between these two types of cracks and whether decarburization is generated near the crack is an important basis for judging the surface defects of the continuous casting bloom.

The formation mechanism of the decarburization layer is that at a certain temperature, the surface of the steel and the surface of the crack (along the extended plane) are oxidized by oxygen atoms in the air, which reduces the carbon content. Due to the loss of carbon, the microstructure around the crack is all ferrite, or between the ferrite region and the matrix.

The nature of decarburization is that the carbon atoms of steel produce heat and then move to the surface to react with oxidizing gases at high temperature. Therefore, the factors that affect carbon diffusion and carbon reaction will influence the occurrence of decarburization. The main factors affecting the decarburization include: the chemical composition of steel, heating temperature, heating time and heating medium. Generally, with the decrease of carbon content in steel, decarburization decreases. With the increase of heating temperature and heating time, the decarburization depth will increase gradually.

3. Influencing Factors of Cracking in Continuous Casting Bloom. The formation of cracks in continuous casting bloom is a complex process, which is the interaction result of heat transfer, mass transfer and deformation [7]. For the high-temperature bloom with the liquid core, the external cause of the crack is that the deformation caused by the action of various forces on the high-temperature shell is over the allowable strength and strain of steel. The internal cause is the cracking susceptibility of steel, while the continuous casting machine equipment and process factors are the conditions for the occurrence of cracks.

3.1. Effect of Carbon Content on Cracks in Continuous Casting Bloom. The carbon content of YQ450NQR1 steel is 0.09 to $0.14 \%$, belonging to hypo-peritectic steel. The hypo-peritectic steel undergoes a peritectic reaction $L+\delta \rightarrow \gamma$ during the solidification process, and volume shrinkage in the process of transforming from $\delta$ ferrite (density 0.68 ) to $\gamma$ austenite (density of 0.74 ) makes the bloom shell to separate prematurely from the mold wall, resulting in an air gap that reduces the heat flux at the location. Then the shell becomes thinner and the austenite grains are coarse [8-10]. When the tensile stress acts on the surface, the stress concentration will occur at the thinner part of the shell with great crack sensitivity. The acid pickling results of the transverse section of the continuous cast bloom show that there is a significant contraction near the inner arc corner and the location of the crack is consistent with the contraction. In the actual production, the carbon content of finished products should be controlled within the range of 0.09 to $0.10 \%$ which could slow down the formation of cracks in continuous casting bloom.

3.2. Effect of Residual Elements on Cracks in Continuous Casting Bloom. In order to improve the atmospheric corrosion resistance, the content of $\mathrm{Cu}$ is generally controlled within $0.20-0.30 \%$. It can be seen that there is $\mathrm{Cu}$ enrichment in the crack from the surface crack fracture analysis. The liquid-phase $\mathrm{Cu}$ permeates the austenite grain boundary and greatly reduces its binding force. The addition of $\mathrm{Sn}, \mathrm{Sb}$, and As enhances the copperinduced embrittlement of the steel. The statistic results show that the residual element content of YQ450NQR1 steel is always high and the occurrence rate of cracking rises with the content of residual elements. 
Studies have shown that the primary austenite is unusually coarse, even if the residual element content is not very high, it can still be enriched at grain boundaries. The original austenite near the crack has exceeded the critical size of coarse austenite grain of $1 \mathrm{~mm}$. The coarse austenite grains produced by the poor heat transfer due to the shrinkage are the reason that the steel is prone to cracking [11-13]. In the actual production, the copper content is controlled in the lower limit to avoid excessive copper enrichment, slowing the formation of cracks in continuous casting bloom.

3.3. Effect of Melt Purity on Continuous Casting Bloom Cracking. The inclusions in the molten steel can be the nuclei of crack and pollute the austenite grain boundary, violating the matrix continuity. When the strand shell is stressed, the stress concentration is generated around the inclusions; thus, cracks are more likely to occur.

The cleanliness of bloom was determined by counting the number and composition of slag inclusions through the large sample electrolysis, the scanning electron microscopy and the energy spectrum analysis. Large sample electrolysis was mainly used to analyze large inclusions greater than $50 \mu \mathrm{m}$ in steel. Table 1 shows the results of the total amount and size distribution of oxide inclusions larger than $50 \mu \mathrm{m}$. It can be seen that the inclusions of large particles in the bloom are mainly concentrated in that of $80 \sim 140 \mu \mathrm{m}$.

T a b 1 e 1

The Total Content of Inclusions and Their Size Distribution in YQ450NQR1 Bloom

\begin{tabular}{|c|c|c|c|c|c||}
\hline \multirow{2}{*}{$\begin{array}{c}\text { Original } \\
\text { sample } \\
\text { number }\end{array}$} & $\begin{array}{c}\text { Total } \\
\text { inclusions } \\
(\mathrm{mg} / 10 \mathrm{~kg})\end{array}$ & $\begin{array}{c}|c| \\
\text { Size classification of inclusion particles }\end{array}$ \\
\cline { 3 - 6 } & $(\%)$ & $\begin{array}{c}<0 \mathrm{~m} \\
(\%)\end{array}$ & $\begin{array}{c}80 \sim 140 \mu \mathrm{m} \\
(\%)\end{array}$ & $\begin{array}{c}140 \sim 300 \mu \mathrm{m} \\
(\%)\end{array}$ \\
\hline 1 & 10.47 & 6.7 & 53.3 & 33.3 & 6.70 \\
\hline 2 & 11.28 & 12.5 & 68.8 & 12.5 & 6.25 \\
\hline 3 & 5.88 & 30.0 & 60.0 & 10.0 & - \\
\hline
\end{tabular}

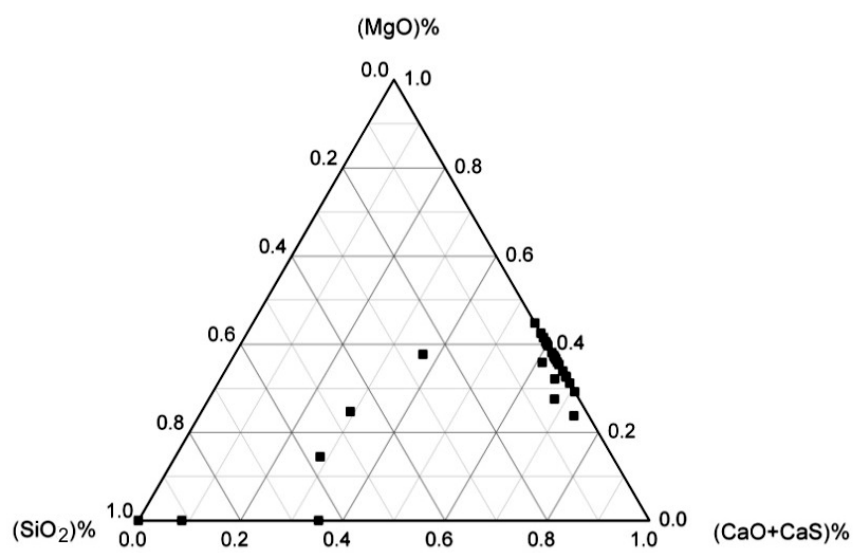

Fig. 4. Composition of inclusions by the large-sample electrolysis.

The composition of the inclusions was analyzed using large electrolytic samples. Figure 4 indicates that inclusions of size greater than $50 \mu \mathrm{m}$ are mainly $\mathrm{CaO}+\mathrm{MgO}$, except for a small amount of those containing $\mathrm{SiO}_{2}$.

Meanwhile, the inclusions in the cracks were examined with the scanning electron microscopy. As seen in Fig. 5, inclusions in cracks are $\mathrm{A} 1, \mathrm{Mg}, \mathrm{Si}, \mathrm{Ca}$ composite, pure 


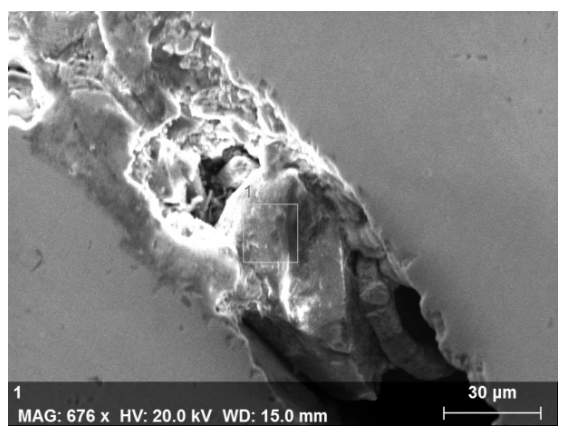

a

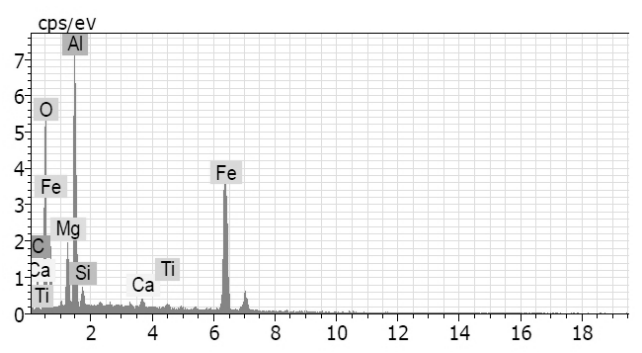

b

Fig. 5. Morphology (a) and composition (b) of non-metallic inclusions in crack.

$\mathrm{Al}_{2} \mathrm{O}_{3}$, and $\mathrm{CaO}+\mathrm{MgO}$ oxide. These inclusions violate the matrix continuity. As stresses in the matrix and inclusions are different, when the solid shell of bloom is stressed, the stress concentration occurs near inclusions and cracking is more likely.

In the process of the actual operation, the molten steel was subjected to calcium treatment after the refinement, and the morphology of $\mathrm{Al}_{2} \mathrm{O}_{3}$ inclusions was changed. The lack of processing time resulted in the fact that there was no sufficient time for inclusions to float, increasing the probability of cracks in the continuous casting bloom. Then the argon blowing was too violent in the calcium treatment process, so the molten steel was exposed, leading to the secondary oxidation of molten steel and aggravating the formation of inclusions. To improve the molten steel purity, the converter slag-retaining technique was applied to avoid the slag tapping. In the tapping process, a small flow of argon blowing was adopted. At the end of tapping, $200 \mathrm{~kg}$ high-aluminum slag agent was added to the slag surface to modify the top slag. The white slag in the refining process was rapidly produced, and then was cooled down for 15 minutes to float the inclusions. In the casting process, a long nozzle seal was utilized to protect the melt, and to avoid the secondary oxidation of the molten steel during the casting process.

3.4. Effects of Mold Powder on Cracks in Continuous Casting Bloom. Analyzing the fracture of the mesh crack further demonstrated that such a crack source mainly generated in the mold. Poor performance of mold powder in lubrication and heat transfer effect is an important factor that leads to the mold cracking.

The relationship between the mold powder used in the production of the high-strength weather-resistant steel and the surface crack of the bloom is shown in Fig. 6. When the melting point of the mold powder is between 1075 and $1100^{\circ} \mathrm{C}$, the occurrence rate of cracks is less than $5 \%$. When the melting point of the mold powder is higher than $1100^{\circ} \mathrm{C}$, the rate of the surface crack increases significantly with the melting point. By adjusting the composition ratio, the melting point of the slag was controlled at about $1086^{\circ} \mathrm{C}$, which effectively inhibited the formation of cracks.

The viscosity of the mold powder directly affects its consumption per ton steel and the thickness as well as uniformity of the flux film between the copper mold and the bloom shell. Mills et al. found that when the viscosity $(\eta)$ and the pulling speed $(V)$ satisfies $\eta V=$ $=0.3 \sim 0.5 \mathrm{~Pa} \cdot \mathrm{s} \cdot \mathrm{m} / \mathrm{min}$, the molten flux layer between the mold and the bloom can be guaranteed with appropriate lubrication performance [14]. The current casting speed is $0.5 \mathrm{~m} / \mathrm{min}$, therefore, it is necessary to ensure that the mold powder viscosity is over 0.6.

3.5. Effects of the Secondary Cooling Intensity on Cracks in the Continuous Casting Bloom. For steels containing microalloying elements such as $\mathrm{Nb}, \mathrm{V}$, and $\mathrm{Ti}$, an effective measure to prevent the occurrence of horizontal and mesh cracks on the bloom is to use a Gleeble thermal simulator to determine the transition temperature of the third 


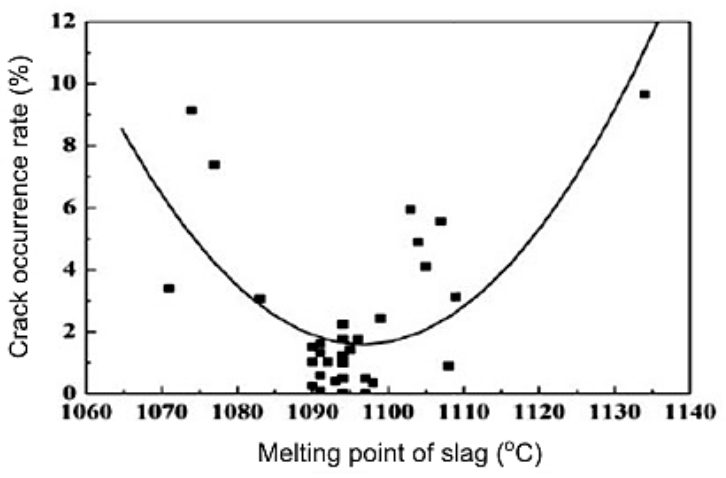

Fig. 6. The relationship between melting point of mold powder and bloom cracks.

brittle zone for the control of the water flux distribution of secondary cooling, so that the straightening temperature of strand is higher than this temperature.

The tensile strength and cross-sectional reduction of YQ450NQR1 steel with temperature were measured by a Gleeble thermal simulator. By checking a number of literatures with practical experience $[1,3,7]$, it is generally believed that the cross-sectional reduction ratio large than $60 \%$ represents better plasticity, while it less than $60 \%$ means poor plasticity. Test results showed that the third brittle zone temperature limit of continuous bloom of YQ450NQR1 steel is about $917^{\circ} \mathrm{C}$. For vanadium nitrogen microalloyed steels, when the straightening temperature is higher than the upper limit of the temperature of the third brittle zone, it can prevent the occurrence of cracks in continuous casting bloom [15-17].

In order to predict the temperature at straightening point in the bloom during the current process, the two-dimensional heat transfer model was established [18], and the temperature at the straightening point with the current water flux distribution program was predicted. Table 2 illustrates the original and current water flux distribution programs.

T a b 1 e 2

Secondary Cooling System of Continuous Casting Bloom of YQ450NQR1 Steel

\begin{tabular}{||c|c|c|c|c|c|c|c|c||}
\hline \hline \multirow{2}{*}{$\begin{array}{c}\text { Casting } \\
\text { speed } \\
(\mathrm{m} / \mathrm{min})\end{array}$} & \multirow{2}{*}{$\begin{array}{c}\text { Secondary } \\
\text { cooling } \\
\text { process }\end{array}$} & $\begin{array}{c}\text { Water } \\
\text { cooling } \\
\text { zone }\end{array}$ & $\begin{array}{c}\text { Specific } \\
\text { water } \\
\text { flow rate } \\
(1 / \mathrm{kg})\end{array}$ & \multicolumn{3}{|c|}{ Secondary water distribution ratio (\%) } \\
\cline { 5 - 9 } & & Area 1 & Area 2 & Area 3 & Area 4 & Area 5 \\
\hline 0.5 & $\begin{array}{c}\text { Original water } \\
\text { distribution (1) }\end{array}$ & $1 \sim 4$ & 0.296 & 18.74 & 24.66 & 18.63 & 37.97 & 0 \\
\hline 0.5 & $\begin{array}{c}\text { Original water } \\
\text { distribution (2) }\end{array}$ & $1 \sim 5$ & 0.332 & 16.72 & 25.32 & 16.62 & 25.17 & 16.18 \\
\hline 0.5 & $\begin{array}{c}\text { Current water } \\
\text { distribution }\end{array}$ & $1 \sim 5$ & 0.308 & 18.01 & 27.28 & 17.90 & 27.12 & 9.69 \\
\hline
\end{tabular}

In view of the original water flux distribution program and the current process of $0.5 \mathrm{~m} / \mathrm{min}$ casting speed, a $1540^{\circ} \mathrm{C}$ pouring temperature, and a $0.3321 / \mathrm{kg}$ specific water flow rate, the temperature variation under the original cooling condition was calculated as shown in Fig. 7. In the length range of 20.35 24.85 $\mathrm{m}$ (straightening interval), the bloom surface temperature is $905 \sim 860^{\circ} \mathrm{C}$ and the corner temperature is $715 \sim 697^{\circ} \mathrm{C}$, indicating that 


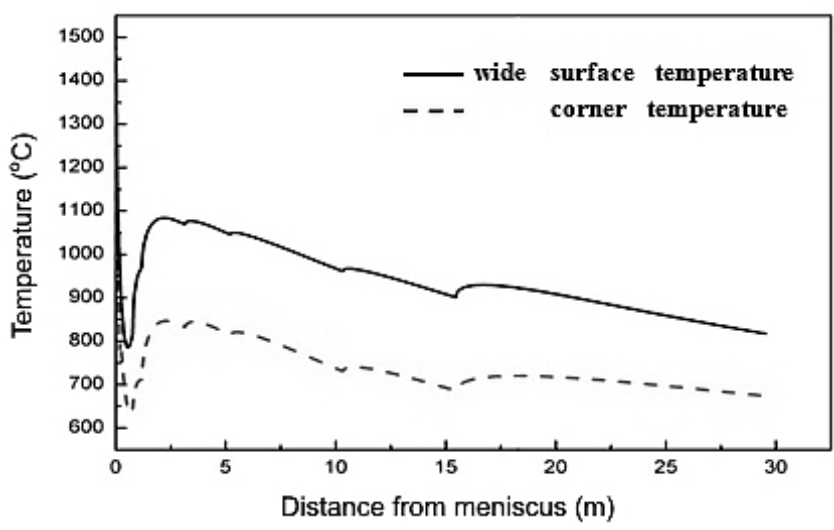

Fig. 7. The temperature distribution in the wide surface and the corner of bloom along the casting direction.

the surface temperature is within the temperature range of the third brittle region. When the bloom was straightened, the inner arc surface was subjected to the tensile stress while the outer arc surface was subjected to the compressive stress. As the tensile stress generated at the root of the inner arc was concentrated, it made the inner arc surface and subcutaneous area easy to crack.

Similarly, prediction of surface temperature on the continuous casting bloom was carried out with the optimized water flux distribution and the same model, and finally the surface temperature requirement out of the third brittle region was satisfied. As can be seen from Table 3, the relative error between calculated temperature of the model and the measured temperature is less than $3 \%$, and that in the straightening area is even within $1 \%$.

T a b 1 e 3

Comparison of Calculated and Measured Temperatures on the Bloom Surface

\begin{tabular}{|c|c|c|c|c|c|c|}
\hline Characteristic & $\begin{array}{c}\text { Exit } \\
\text { of area } 3\end{array}$ & $\begin{array}{c}\text { Exit } \\
\text { of area } 4\end{array}$ & 2\# SME & 3\# SME & 4\# SME & 5\# SME \\
\hline $\begin{array}{l}\text { Measured temperature } \\
\text { with original water } \\
\text { distribution }(1)\left({ }^{\circ} \mathrm{C}\right)\end{array}$ & 1013.0 & 933.0 & 871.0 & 851.0 & 843.0 & 827.0 \\
\hline $\begin{array}{l}\text { Model calculated } \\
\text { value }\left({ }^{\circ} \mathrm{C}\right)\end{array}$ & 1027.3 & 912.9 & 874.5 & 859.4 & 845.1 & 831.5 \\
\hline Relative error (\%) & 1.41 & 2.15 & 0.40 & 0.99 & 0.25 & 0.54 \\
\hline $\begin{array}{l}\text { Measured temperature } \\
\text { with original water } \\
\text { distribution }(2)\left({ }^{\circ} \mathrm{C}\right)\end{array}$ & 1009.0 & 960.0 & 866.0 & 846.0 & 835.0 & 819.0 \\
\hline $\begin{array}{l}\text { Model calculated } \\
\text { value }\left({ }^{\circ} \mathrm{C}\right)\end{array}$ & 1036.5 & 940.9 & 859.4 & 845.3 & 832.0 & 819.2 \\
\hline Relative error (\%) & 2.73 & 1.99 & 0.76 & 0.08 & 0.36 & 0.02 \\
\hline
\end{tabular}

Note. SME is straightening machine entrance.

With the process improved according to the above influence factors optimization, the cracking reject ratio during rolling was reduced from 3.5 to $0.78 \%$ in the plant. 


\section{Conclusions}

1. Significant decarburization layer was found in cracks of YQ450NQR1 high-strength weathering steel, which indicated that crack fracture originated from the continuous casting bloom.

2. The carbon content of YQ450NQR1 steel in the range of hypo-peritectic reaction and copper added to improve the corrosion resistance aggravated cracking in the continuous casting bloom.

3. To reduce cracks in the continuous casting bloom, the melting point of mold powder should be controlled between $1050 \sim 1100^{\circ} \mathrm{C}$ to improve the purity of molten steel, and the slag viscosity should be limited at 0.6.

4. When the straightening zone temperature is higher than $917^{\circ} \mathrm{C}$, the occurrence of cracks can be improved in the continuous casting bloom.

1. J. S. Qing, H. F. Shen, and M. Liu, "V-N microalloying of high strength weathering steel YQ450NQR1," Iron Steel, 52, No. 5, 87-93 (2017).

2. J. S. Qing, L. Wang, K. Dou, et al., "Influence of $\mathrm{V}-\mathrm{N}$ microalloying on the high-temperature mechanical behavior and net crack defect of high strength weathering steel," High Temp. Mater. Proc., 35, No. 6, 575-582 (2016).

3. D. Chen, L. Song, Z. Dong, et al., "Effect of cooling rate on high temperature mechanical properties of weathering steel," J. Chongqing Univ., 34, No. 11, 50-55 (2011).

4. L. Liu and Z. Li, "Cracking analysis of $310 \mathrm{Z}$ shape steel," Phys. Test., 29, No. 1, 34-36 (2011).

5. M. Zhang, X. Zhao, Y. Zhu, et al., "Hot ductility of low carbon Nb-microalloyed weathering steel," Adv. Mater. Res., 887-888, 200-206 (2014).

6. X. Wu, Y. Wan, Z. Zhang, et al., "Research on cracking sensitivity of weathering steel SMA490BW," in: Proc. of the 2014 Int. Conf. on Mechatronics, Control and Electronic Engineering: Advances in Intelligent Systems Research, 113, 372-375 (2014).

7. S. Luo, Study and Application of Casting Solidification and Heat Transfer Model of $360 \mathrm{~mm} \times 450 \mathrm{~mm}$ Continuous Casting Billet's Online [in Chinese], Northeastern University (2008).

8. J. Qu and Z. Wang, "Prediction model of controlled rolling and controlled cooling in the austenitic phase transformation behavior," J. Iron Steel Res., 10, No. 5, 41-43 (1998).

9. B. Mintz, "The influence of composition on the hot ductility of steels and to the problem of transverse cracking," ISIJ Int., 39, No. 9, 833-855 (1999).

10. G. Cardoso, B. Mintz, and S. Yue, "Hot ductility of aluminium and titanium containing steels with and without cyclic temperature oscillations," Ironmak. Steelmak., 22, No. 5, 365-377 (1995).

11. X. Wang, W. Wang, and X. Liu, "Research on reducing the Nb, V, Ti microalloyed steel cc slab corner transverse cracks," Iron Steel, 33, No. 1, 22-25 (1998).

12. L. Li and H. Gong, "Production practice of steel YQ450NQR1 steel for railway vehicles," in: Proc. of the Fourteenth National Conference on Steelmaking (2006).

13. B. Mintz, "Importance of $\mathrm{Ar}_{3}$ temperature in controlling ductility and width of hot ductility trough in steels, and its relationship to transverse cracking," Mater. Sci. Tech., 12, No. 2, 132-138 (1996). 
14. H. Kobayashi, "Hot-ductility recovery by manganese sulphide precipitation in low manganese mild steel," ISIJ Int., 31, No. 3, 268-277 (1991).

15. D. N. Crowther, Z. Mohamed, and B. Mintz, "Influence of micro-alloying additions on the hot ductility of steels heated directly to the test temperature," Trans. Iron Steel I. Jpn., 27, No. 5, 366-375 (1987).

16. K. Cai and Y. Zhang, "The high temperature mechanical properties of cast steel album," J. Univ. Sci. Technol. B., 15, No. 2, 3-20 (1993).

17. Y. Kang and J. Han, Process Principle and Control Solid Forming [in Chinese], National Defense Industry Press, Beijing (2002).

18. K. Dou, J. S. Qing, L. Wang, et al., "Research on internal crack susceptibility of continuous-casting bloom based on micro-segregation model," Acta Metall. Sin., 50, No. 12, 1505-1512 (2014). 